\title{
Reaching the horizon and looking beyond: neurosurgery education in Kazakhstan
}

\author{
Serik Akshulakov, MD, PhD, ${ }^{1}$ Yerbol Makhambetov, MD, PhD, ${ }^{1}$ Askhat Bralov, MD, PhD, ${ }^{1}$ \\ Talgat Pazylbekov, MD, PhD, ${ }^{1}$ Nurtas Tursynov, MD, PhD, ${ }^{2}$ and Karashash Menlibayeva, MPH $^{1}$
}

\begin{abstract}
${ }^{1}$ National Center for Neurosurgery, Nur-Sultan; and ${ }^{2}$ Karaganda Medical University, Karaganda, Kazakhstan
Neurosurgery education in Kazakhstan has 55 years of history. The first neurosurgery department was established in 1964 in the city of Almaty, South Kazakhstan (the former capital of Kazakhstan). The department was headed by the pioneer of Kazakhstani neurosurgeons, Prof. Yevgeniya Azarova. A new neurosurgery education system was adopted after a while. To date, 4 medical universities and 1 neurosurgical center in Kazakhstan have a neurosurgery department that prepares around 10 neurosurgeons annually. The country's populations are currently served by more than 300 neurosurgeons. However, isolated regions lack neurosurgical services and a specialized medical workforce. Urbanization results in inequality of receiving medical care among rural and regional inhabitants.

To develop and strengthen the neurosurgery services, the National Center for Neurosurgery was opened in the heart of the country. The center has placed great importance on the development of neurosurgery and neurosurgical education in Kazakhstan. The World Federation of Neurosurgical Societies, European Association of Neurosurgical Societies, Asian Congress of Neurosurgeons, and International Society for Pediatric Neurosurgery have held many international meaningful events on neurosurgery at the center. Opened in 2008, the neurosurgery center has prepared 41 neurosurgeons in the residency program. This article seeks to provide readers with an understanding of the state of neurosurgery education in Kazakhstan and its development history.

https://thejns.org/doi/abs/10.3171/2019.12.FOCUS19790
\end{abstract}

KEYWORDS neurosurgical education; Kazakhstan; National Center for Neurosurgery

$\mathrm{D}$ EVELOPMENT and maintenance of neurosurgical training have always been important, especially nowadays due to improvements in diagnosis and treatment of neurological and neuro-oncological disorders that affect billions of people worldwide. Due to longer lifespans, the proportion of older people is growing in many countries. According to the WHO's projections, the prevalence of neurological disorders, particularly Alzheimer's and other dementias and Parkinson's disease, will increase gradually by $2030 .^{7}$ Diseases like brain trauma due to road injuries, ischemic heart disease, and stroke are on the list of the leading causes of deaths and disability worldwide, ${ }^{1}$ and the frequent cause of stroke is a condition requiring neurosurgical treatment. Furthermore, middle-income countries have the highest annual road traffic fatalities affecting the working-age population, mainly caused by brain trauma and whiplash. ${ }^{6}$ In addition, the global burden of disability is driven mainly by low-back pain, headache disorders, and depression. ${ }^{1}$

Trauma and injuries are the fourth reason for fatality after cancer, cardiovascular, and respiratory diseases in Kazakhstan. ${ }^{3}$ Therefore, the government is aware of the importance of training of neurosurgeons available to care for neurosurgical disorders.

Educating young specialists is important at this time when the developing world is facing an emigration of the youngest, the brightest, and the ablest minds, which has resulted in "brain drain."

Neurosurgery education in Kazakhstan dates back to 1959 when the "courses of docents for neurosurgery" started at Kazakh Medical University of postgraduate medical education in Almaty City (the former capital of Kazakhstan). The courses were held for 3 years, and in September 1962, they had been transformed into the educational neurosurgery department, which has fully operated since 1964. The first head of the department was Prof. Yevgeniya Azarova, followed by Prof. Beremzhanova, Prof. Aiginson, Prof. Akshulakov, and currently headed by Prof. Dyusembekov.

Many talented and high-skilled neurosurgeons have 
TABLE 1. The educational pathways to becoming a neurosurgeon in Kazakhstan

\begin{tabular}{|c|c|c|c|c|}
\hline \multicolumn{3}{|c|}{ Old Educational Pathway (1964-2008) } & \multicolumn{2}{|r|}{ New Educational Pathway (since 2008) } \\
\hline \multicolumn{3}{|c|}{ General practitioner after graduation from medical university ( 5 yrs) } & Step 1 & General practitioner after graduation from medical university ( 5 yrs) \\
\hline \multicolumn{3}{|c|}{ General surgery internship at medical university (1 yr) } & Step 2 & General surgery internship at medical university ( 2 yrs) \\
\hline $\begin{array}{l}\text { Clinical residency in neuro- } \\
\text { surgery ( } 2 \text { yrs) }\end{array}$ & or & $\begin{array}{l}\text { Neurosurgery initial training } \\
\text { (5 mos) }\end{array}$ & Step 3 & Mandatory clinical residency in clinical neurosurgery (4 yrs) \\
\hline Neurosurgeon & & & Step 4 & Neurosurgeon \\
\hline
\end{tabular}

graduated from the program, including those working and saving dozens of people's lives every day at the National Center for Neurosurgery in the country's capital, NurSultan. In addition to training local neurosurgeons, the department had been a training ground for neurosurgeons from certain countries of the former Soviet Union.

Currently, 4 medical universities and 1 neurosurgical center provide postgraduate training in neurosurgery: Asfendiyarov Kazakh National Medical University in Almaty City, Kazakh Medical University of postgraduate medical education in Almaty City, Karaganda Medical University in Karaganda City, West Kazakhstan Marat Ospanov Medical University in Aktobe City, and National Center for Neurosurgery in Nur-Sultan.

Before 2008, those pursuing a career in neurosurgery needed to complete a 1-year general surgery internship at a medical university. Then, general surgeons had 2 choices: doing either a 2-year clinical residency or a 5-month initial training to become a neurosurgeon. The only difference was that initial training graduates worked primarily in neurotrauma and emergency neurosurgery units. Neurosurgeons in Kazakhstan trained under this system for 44 years until the 4-year residency program was introduced in 2008. The educational pathways to becoming a neurosurgeon in Kazakhstan are shown in Table 1.

The Ministry for Education and Science in Kazakhstan adopted the standard for neurosurgery training, which guides all that the medical universities and neurosurgery center do. According to the standard, since 2008, general surgeons must complete a 4-year neurosurgical residency program. The new educational pathway aimed to train an adequate number of neurosurgeons who would bring quality neurosurgical care and expertise to the most remote areas of the country.

\section{Methods}

Current data on the residency training program and the number of neurosurgical residents trained in Kazakhstan, the number of practicing neurosurgeons, the number of operated and treated cases, and information regarding the population were derived from the statistics departments at the Ministry of Healthcare of Kazakhstan and the National Center for Neurosurgery. The t-test was calculated to assess the increase in the number of educated neurosurgeons.

\section{Results}

Given a large land area, the ninth largest in the world, Kazakhstan is divided into 17 regions geographically. With a population of 18.6 million people as of December $2018,{ }^{4}$ the population density is among the lowest, at 6.82 people $/ \mathrm{km}^{2}{ }^{5}$ Kazakhstan's people are served by 327 neurosurgeons with a ratio of 1.758 neurosurgeons to 100,000 population; the required minimum number of neurosurgeons is 1.500 to 100,000 people in Kazakhstan. ${ }^{2}$ Despite that, the distribution of neurosurgeons in different regions of the country is uneven. Neurosurgeons are in high demand in the northern and western parts of the country.

The geographic and population data for Kazakhstan, the ratio of neurosurgeons, and the number of cases treated and operated on are presented in Table 2.

\section{The Neurosurgery Residency Program at the National Center}

Around 10 physicians in Kazakhstan have become neurosurgeons annually since adopting the new 4-year neurosurgical residency program in 2008. At the same time, in

TABLE 2. Neurosurgery services in Kazakhstan in 2008 and 2018

\begin{tabular}{lcc}
\hline & 2008 & 2018 \\
\hline Area $\left(\mathrm{km}^{2}\right)$ & \multicolumn{2}{c}{$2,724,900$} \\
\hline Population (million) & 15.7 & 18.6 \\
\hline Population density/km ${ }^{2}$ & 5.75 & 6.82 \\
\hline No. of neurosurgeons & 243 & 327 \\
\hline No. of neurosurgeons $/ 100,000$ population & 1.547 & 1.758 \\
\hline No. of neurosurgeons/area $\left(100 \mathrm{~km}^{2}\right)$ & 0.008 & 0.012 \\
\hline No. of cases operated on & 6116 & 10,649 \\
\hline No. of cases treated & 31,003 & 43,623 \\
\hline
\end{tabular}


TABLE 3. Neurosurgeons trained in Kazakhstan between 2012 and 2018

\begin{tabular}{lccccccc}
\hline & 2012 & 2013 & 2014 & 2015 & 2016 & 2017 & 2018 \\
\hline Total no. in Kazakhstan & 3 & 5 & 11 & 12 & 12 & 17 & 10 \\
\hline No. at National Center $(\%)$ & $2(66.7)$ & $4(80.0)$ & $4(36.4)$ & $5(41.6)$ & $4(33.3)$ & $7(41.2)$ & $7(70.0)$ \\
\hline
\end{tabular}

the summer of 2008, the National Center for Neurosurgery was opened in Nur-Sultan, becoming a new starting point in the development of neurosurgical education. The first neurosurgeons who attended a 4-year residency program graduated in 2012. The center has been preparing nearly half of the neurosurgeons in Kazakhstan during the last 7 years, as summarized in Table 3 .

The Department and Faculty for Education supervise the neurosurgery education program at the National Center. Clinical units with a wide range of subspecialties such as neuro-oncology, spinal neurosurgery, micro- and endovascular neurosurgery, functional neurosurgery, pediatric neurosurgery, neurosurgery of the peripheral nervous system, neurology, neurorehabilitation, and diagnostics serve as a clinical basis for trainees. In addition to Kazakhstani citizens, residents of Georgia and Nigeria have completed a neurosurgical residency at the National Center.

The center's neurosurgical training program has the following levels. The first level during the first 2 years of training is to acquire theoretical knowledge of neurosurgery. Second-level trainees apply their knowledge to practice and perform neurosurgical procedures under supervision in their 3rd year of training. The third level, the final year of training, is becoming a neurosurgeon with the ability to perform procedures independently. Trainees practicing at the National Center are shown in Fig. 1.

\section{International Internships, Fellowships, Staff Development, and Educational Courses for Neurosurgeons}

Neurosurgeons in Kazakhstan enrich their knowledge and professional skills by attending various international educational courses, internships, and fellowships. The number of neurosurgeons educated in such programs has largely increased over the past 5 years compared with before. The number of neurosurgeons educated over the past 10 years is grouped and tabulated in Table 4 .

\section{Discussion}

The neurosurgery education system in Kazakhstan is not very different from systems in the countries of the Commonwealth of Independent States. Being under one common government for 70 years affected all the spheres, including medical education. Higher-education diplomas issued in the countries of the Commonwealth are recognized by each member country, so neurosurgeons can train and practice wherever they desire across the Commonwealth countries.

In 2010, Kazakhstan officially joined the Bologna declaration and became the first country in Central Asia that was recognized as a full member of the European educational area. The country has signed various treaties on academic mobility with European countries.

Kazakhstani citizens have an opportunity to study abroad through the fully funded international Bolashak scholarship program, which was established in 1993. At the VIII International Going Global Conference in Miami, Florida, in 2014, the Bolashak Scholarship was named the best among 11 academic mobility programs. There are now more than 10,000 graduates of the world's top 50 universities, including 136 clinical residency doctors, of which 5 are neurosurgeons. Specialists trained abroad come to Kazakhstan to practice, as the program requires students to return and work for 5 years in national organizations.

\section{Neurosurgical Educational Events on Neurosurgery in Kazakhstan}

The Kazakh Association of Neurosurgeons was created in 2010 in Kazakhstan. The president of the association is Prof. Serik Akshulakov, and the honorary members are Prof. Yoko Kato, Prof. Peter Black, Prof. Madjid Samii, Prof. Saleem Abdulrauf, Prof. Alexander Konovalov, Prof. Alexander Potapov, and Prof. Leonid Lihterman. The association is an active member of the European Association of Neurosurgical Societies (EANS), World Federation of Neurosurgical Societies (WFNS), and Asian Congress of Neurological Surgeons.

Many international congresses and conferences on neurosurgery have been held in Kazakhstan since the establishment of the Kazakh Association of Neurosurgeons. The WFNS provided educational courses in 2011, and EANS educational courses were organized in 2015. Kazakhstan became the venue of the 10th Asian Congress of Neurological Surgeons in 2014. The Second Congress of Eurasian Association of Pediatric Neurosurgery was held in the summer of 2019, during which Kazakhstan host-

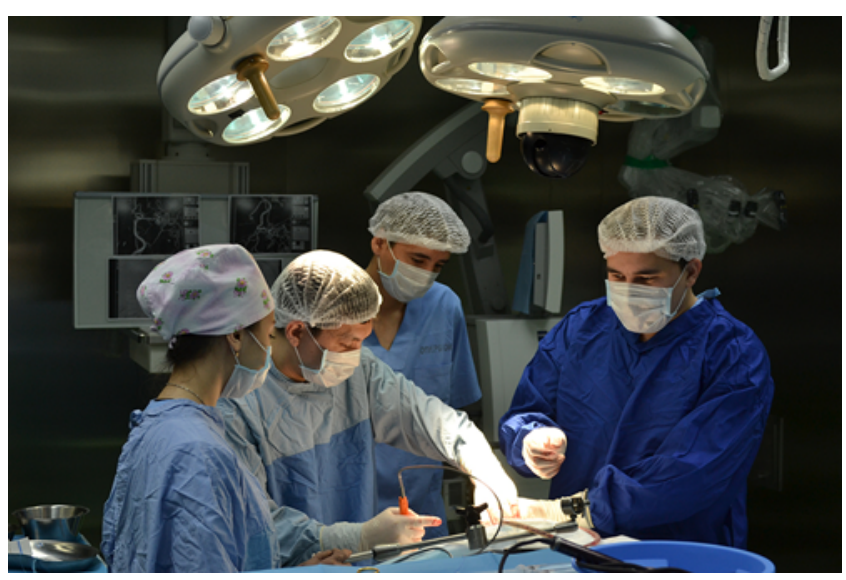

FIG. 1. Neurosurgery trainees practicing at the National Center, April 2017. 
TABLE 4. Attendance of neurosurgeons at various international educational courses, internships, and fellowships between 2009 and 2018

\begin{tabular}{lccccc}
\hline & No. of Educated Neurosurgeons & Mean No. in Attendance & SD & SEM & $p$ Value \\
\hline Group 1 (2009-2013) & 393 & 78.60 & 61.51 & 27.51 & \multirow{2}{*}{0.004} \\
\hline Group 2 (2014-2018) & 1225 & 245.00 & 71.64 & 32.04 & \\
\hline
\end{tabular}

ed the International Society for Pediatric Neurosurgery courses of pediatric neurosurgery. The Congress of 2019 attracted hundreds of pediatric neurological surgeons and residents from around the globe. In addition, educational courses on stroke problems have been held since the establishment of the Stroke Center at the Neurosurgery Center in 2016. The stroke center coordinates medical care for stroke patients throughout the country, and there are now 59 centers functioning in Kazakhstan.

\section{Conclusions}

Neurosurgery education in Kazakhstan has faced many challenges and changes. The most important change in the past 10 years has undoubtedly been the establishment of a 4 -year residency training program. The program aims to train an adequate number of highly specialized neurosurgeons who treat a full range of neurosurgical disorders. However, some regions in Kazakhstan are still in need of neurosurgical workforces, particularly pediatric neurosurgeons. The equity and equality in the access to the neurosurgical services should be provided by government regulation and policy in structuring medical education and the allocation of staff resources.

\section{References}

1. Institute for Health Metrics and Evaluation: Findings From the Global Burden of Disease Study 2017. Seattle, WA: IHME, 2018, pp 10-13

2. Ministry of Healthcare of Kazakhstan: The Required Number of Physicians in Kazakhstan. Nur-Sultan: Ministry of Healthcare of Kazakhstan, 2010 (http://adilet. zan.kz/rus/docs/V100006173) [Accessed January 14, 2020]

3. Ministry of National Economy of the Republic of Kazakhstan Statistics Committee: Mortality Rate of the Population in Kazakhstan. Nur-Sultan: Statistics Committee, 2019 (https://stat.gov.kz/) [Accessed January 14, 2020]

4. Ministry of National Economy of the Republic of Kazakh- stan Statistics Committee: Population of Kazakhstan. Nur-Sultan: Statistics Committee, 2019 (http://stat.gov.kz/) [Accessed January 14, 2020]

5. World Bank: World Bank Country and Lending Groups. Washington, DC: World Bank, 2019 (https://datahelpdesk. worldbank.org/knowledgebase/articles/906519-world-bankcountry-and-lending-groups) [Accessed January 14, 2020]

6. World Health Organization: Global Status Report on Road Safety 2013. Geneva: World Health Organization, 2013 (https://www.who.int/violence_injury_prevention/road_ safety_status/2013/en/) [Accessed January 14, 2020]

7. World Health Organization: Neurological Disorders: Public Health Challenges. Geneva: World Health Organization, 2006 (https://www.who.int/mental_health/neurology/ neurodiso/en/) [Accessed January 14, 2020]

\section{Disclosures}

The authors report no conflict of interest concerning the materials or methods used in this study or the findings specified in this paper.

\section{Author Contributions}

Conception and design: Akshulakov, Makhambetov, Pazylbekov. Drafting the article: Menlibayeva, Akshulakov. Critically revising the article: Akshulakov, Makhambetov, Pazylbekov, Tursynov. Reviewed submitted version of manuscript: Menlibayeva, Makhambetov, Bralov, Pazylbekov, Tursynov. Approved the final version of the manuscript on behalf of all authors: Menlibayeva. Administrative/technical/material support: Menlibayeva, Bralov.

\section{Supplemental Information}

Previous Presentations

Portions of this work were presented in report form at the 2019 WFNS Special World Congress, World Federation of Neurosurgical Societies, Beijing, China, September 9-12, 2019.

\section{Correspondence}

Karashash Menlibayeva: National Center for Neurosurgery, NurSultan, Kazakhstan. kara.mnl.kz@gmail.com. 